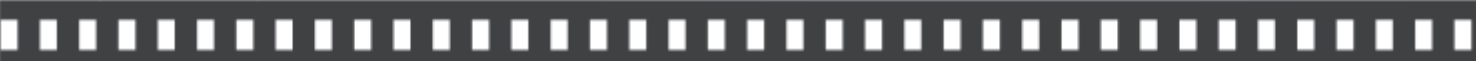

\author{
Entrevista: \\ Alan Taylor
}

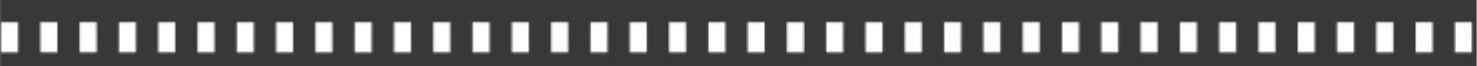

Cristiane Fontinha 


\section{The Big Picture, o blog que revolucionou o modo de ver fotografia na internet}

The Big Picture, the blog that has revolutionized the way of seeing photograph on the internet

\section{Cristiane Fontinha*}

Atentos à tecnologia e preocupados com o poder informativo da imagem, desenvolvedores de conteúdo de tradicionais jornais e revistas impressas investem na construção de novas narrativas na internet. $\mathrm{Na}$ contramão do conteúdo publicado pelas empresas jornalísticas nos meios tradicionais, os blogs têm quebrado paradigmas, ousando utilizar novas linguagens - logo assimiladas e incorporadas pelos portais e jornais online. O entrevistado desta edição é Alan Taylor ${ }^{1}$, criador do blog The Big Picture $^{2}$, que pertence ao jornal The Boston Globe ${ }^{3}$, uma referência importante, que marca esta transição. Criado em 2008, o blog foi sucesso imediato. Em apenas 20 dias chegou a alcançar 1,5 milhão de pageviews e obteve cerca de 1.500 comentários. Assim como o nome revela, traz extensas coberturas em grande formato, sob o ponto de vista de diferentes fotojornalistas. No início de 2011, o criador do blog, que tem oito milhões de pageviews ao mês, levou o projeto - rebatizado de In Focus ${ }^{4}$ - para a revista The Atlantic ${ }^{5}$, sediada em Washington.

\footnotetext{
* Cristiane Fontinha Miranda. Graduada em Comunicação Social - Habilitação Jornalismo pela Universidade Federal de Santa Catarina (UFSC - 1994). Especialista em Fotografia pela Faculdade Senac de São Paulo (2003). Mestranda em Design e Expressão Gráfíca na UFSC, sob orientação da Profa. Dra. Maria José Baldessar. Trabalhou em redações de jornais, inicialmente como repórter de texto e depois como repórter fotográfica. Por quatro anos foi professora de fotografia nos cursos de Jornalismo e Publicidade da Faculdade Estácio de Sá de Santa Catarina. Recentemente foi professora substituta da disciplina de fotojornalismo na Universidade Federal de Santa Catarina (UFSC). Atuou como consultora de fotografia do jornal Notícias do Dia. Atualmente exerce a atividade de fotojornalista freelancer. E-mail: crisfontinha@gmail.com

${ }^{1}$ Alan Taylor acumulava dez anos de experiência como programador e webdesigner quando criou o blog em 2008. Ele nunca trabalhou como fotógrafo.

${ }^{2}$ Disponível em: $<$ http://www.boston.com/bigpicture/ $>$.

${ }^{3}$ Disponível em: <http://www.boston.com/bostonglobe/>

${ }^{4}$ Disponível em: $<$ http://www.theatlantic.com/infocus/>.

${ }^{5}$ Disponível em: $<\underline{\text { http://www.theatlantic.com/ }>\text {. }}$
} 


\section{Alan Taylor}

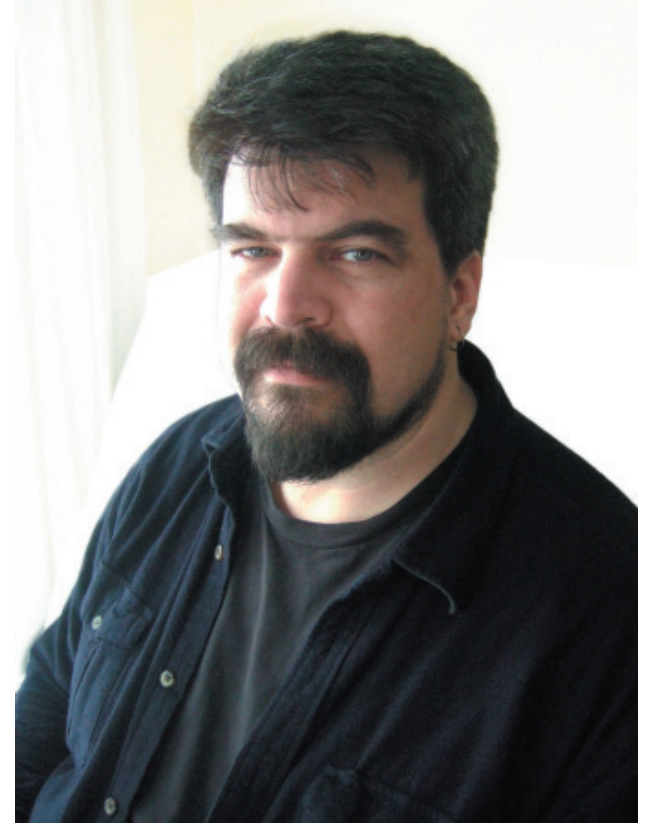

Fotografia: Imagem gentilmente cedida pelo blog Big Picture

Alan Taylor acha que os profissionais estão tendo que fazer várias coisas ao mesmo tempo, como pensar na apresentação, no formato e na composição para dar mais opções aos clientes que estão comprando fotografia. "Não sei se o fotógrafo está sempre buscando uma imagem icônica, mas como editor algumas vezes procuro por uma fotografia representativa, que se destaque”, explica. Ele acredita que há um monte de gente tentando descobrir como fazer dinheiro na internet, não para ficar rico, mas, pelo menos, para cobrir os custos de projetos. E alerta que já há websites para financiamento de projetos com propostas colaborativas. "A ideia é juntar um monte de gente que tem dinheiro e possa contribuir com o fotógrafo para que ele possa realizar o projeto, para depois vendê-lo. Acho uma proposta bacana e estou atento." 


\section{Entrevista}

Cristiane Fontinha - Olhando seu trabalho, o projeto do The Big Picture parece bastante simples. Então, por que ninguém fez algo parecido antes? Você pode explicar?

Alan Taylor - Gostaria de explicar, sim, pois esta é uma pergunta frequente. Agora, que tantos utilizam o mesmo formato, parece simples. Quando comecei não havia nada parecido, ninguém fazia nada igual. Eu tenho algumas teorias, mas nenhuma explica plenamente o porquê. Uma é a de que havia um senso comum entre webdesigners de que não deveriam ser usadas imagens grandes nas telas. Este senso permaneceu por um bom tempo. As conexões eram lentas, os computadores pessoais não conseguiam processar informações grandes e os browsers não eram tão bons. Fazia sentido não querer colocar imagens grandes na tela. E isso virou uma premissa. Além do mais, as telas dos computadores pessoais eram pequenas. A prática permaneceu a mesma por cerca de oito, nove anos. Mas o projeto é mais do que publicar fotografias em grande formato; ele envolve a construção de uma narrativa. É colocar as imagens em uma ordem narrativa. É dificil construir um fluxo narrativo ao contar uma história. Há imagens que têm relação e precisam estar juntas para contar uma história. Quando recebo uma imagem e percebo uma ligação com outras, ainda que sutil, tento relacioná-las com outras imagens com as quais ela tem ligação. Eu realmente presto muita atenção na ordem em que as fotografias são observadas. Minha ideia surgiu de uma frustração, pois eu não estava satisfeito com muitos sites. As páginas desses sites traziam algo parecido com a "foto da semana". Eu olhava para essas imagens e pensava: "São fotografias interessantes, mas são como bala, você pega uma e segue adiante." Não há um envolvimento maior. Você vê uma fotografia maravilhosa, quer mais e não tem para onde ir. Foi por este motivo que comecei o projeto. O que sei é que mostava às pessoas o que estava fazendo e elas diziam: "Uau, isso é fantástico, por que nós não fizemos isso?" 
Cristiane Fontinha - A internet hoje é mais visual que antes. Vi um ensaio sobre o Dia dos Namorados, editado por você, que mostra o tema sob diferentes pontos de vistas, por jornalistas de várias partes do mundo. Como você costura essas histórias?

Alan Taylor-Sim, amo isso. Foi quase acidental. Quando comecei eu não sabia em que estava me metendo: contar essas histórias várias vezes na semana. Quando comecei, editava histórias diariamente, mas tem que ser louco para fazer isso. Minha ideia era que a partir de uma história - como ursos polares nascidos em zoológico ou um tornado ocorrido em algum lugar - eu coletaria o máximo de informações sobre o acontecimento. O que percebi é que as histórias são complementares. É o caso da cobertura do Dia dos Namorados e tantas outras, como o Ramadã ao redor do mundo ou até técnicas de fotografia como silhuetas, foco e gelo podem contar histórias. Começam como temas vagos. Se as pessoas fossem olhar as imagens antes diriam: o que você está fazendo? Essas são apenas fotografias bonitas e não me contam uma história. Outras vezes elas contariam histórias. E eu trabalho duro para isso: descobrir a relação entre as fotografias disponíveis.

Cristiane Fontinha - E como funciona? Você pensa em um tema e vai atrás das fotografias? Como é o andamento do seu trabalho ao longo do dia?

Alan Taylor - Geralmente eu olho as fotografias disponíveis e tento montar uma história a partir delas. Se eu pensar em uma história e for procurar fotografias pode ser frustrante na maioria dos casos, pois estarei empenhado em contar aquela história, sem achar o que estava procurando. Ou achar o que quero, mas achar que as fotografias não são boas o suficiente e comprometerão o trabalho, o que também é frustrante. Sim, muitas vezes eu tive uma ideia e fui em busca de imagens que contassem a história, mas é muito mais difícil desta forma. O caminho mais fácil é olhar um monte de imagens e construir a narrativa a partir delas. Muito mais fácil. 
Cristiane Fontinha - Qual sua formação profissinal? Você é um programador ou designer?

Alan Taylor - Eu tenho uma formação diversificada. Tenho licenciatura em literatura inglesa e especialização em filosofia. Mas já trabalhei em 30 empregos diferentes. Já fui guia de turismo no Alasca, dirigi ônibus um período, já fui operador de planetário e empilhador de revista. Então tive vontade de trabalhar com a internet, porque parecia divertido. Descobri que tinha jeito para isso e passei os últimos 12 anos como desenvolvedor e programador de websites. Acabei trabalhando em muitas empresasas de comunicação. Trabalhei na Msnbc.com, quando era uma empresa recém-criada, por dois anos e meio. Foi quando me mudei de Massachusetts para o estado de Washington. Depois que me estabeleci, consegui o emprego no The Boston Globe. Quando comecei a trabalhar para eles, eu era o desenvolvedor do website da página de classificados. Tive que mostrar o projeto do The Big Picture para um monte de gente, antes de comprarem a ideia. Era um projeto que eu fazia nas horas livres.

Cristiane Fontinha - O que sua experiência como webdesigner trouxe para o jornalismo?

Alan Taylor - Eu não tenho um treinamento específico. Eu tenho amor pelo que faço, pela fotografia, por contar histórias, por imagens maravilhosas e por descobrir coisas novas. Eu sempre tive essas paixões, que herdei da minha mãe. Nós assinávamos as revistas Life e National Geografic quando eu era criança. Lembro que ficava super excitado quando chegavam. Líamos de capa a capa e comentávamos juntos. Eu amava essa experiência. E me parece natural juntar todas essas coisas e contar histórias assim. Como disse, no começo as pessoas olhavam o projeto e não gostavam. Acho que era porque se tratava de uma coisa nova e era difícil de explicar para as pessoas que a proposta era algo básico. Não era mais um slideshow, não era a fotografia do dia, não era nada daquilo. Era uma narrativa em grande formato, que deveria ficar em uma só página e não ter um monte de anúncios. Certamente não entre as 
fotografias. E a maiora das pessoas dizia: OK. Ninguém dizia: sim, isso é maravilhoso!

Cristiane Fontinha - E qual o próximo passo para a fotografia na internet? O que vem agora?

Alan Taylor - Não sei exatamente. Eu acho que tem um monte de gente tentando descobrir como fazer dinheiro na internet. Não tentando ficar rico, mas, pelo menos, para cobrir os custos de projetos. Eu tenho observado alguns projetos. Tem um website chamado Emkphas.is $<\underline{\mathrm{http}}$ :/ /emphas.is/ $>$. Você já ouviu falar? Já ouviu falar do Kickstarter $<\underline{\text { http: } / /}$ www.kickstarter.com/>? São websites para financiamento de projetos de forma colaborativa, crowdfunding. O Emphas.is é voltado para a fotografia. Se um fotógrafo tem um projeto, ele apresenta a proposta, o local e os custos para contar aquela história. Um exemplo, eu preciso de 10 mil dólares para voar até determinado lugar, me manter por determinado período e manter meu equipamento. Quem contribui acaba recebendo um retorno, sejam fotografias ou algo similar. A ideia é juntar um monte de gente que tem dinheiro e possa contribuir com o fotógrafo para que ele possa realizar o projeto, para depois vendê-lo. Acho uma proposta bacana e estou atento.

Cristiane Fontinha - Seu exemplo mostra que combinar design com jornalismo pode criar algo novo? A internet proporciona isso?

Alan Taylor-Definitivamente. Eu acho que há formas tecnológicas diferentes de se mostrar as coisas. Quando fui para a revista The Atlantic $<$ http://www.theatlantic.com/>, eu queria entregar as imagens em dois tamanhos, o tamanho grande padrão e o muito grande. Algo opcional, todo mundo teria o tamanho menor e, se quisesse o grande, também o teria. As opções de exibição se aprimoraram. Se vocês estiverem navegando na internet em sua tela da TV, ou na sua HDTV, as imagens maiores ficam melhores nesses suportes, mais naturais. Se estiver em um monitor de alta resolução, as imagens maiores também são excelentes, ficam mais naturais. Não me preocupo tanto com os pequenos aparelhos 
móveis. Sei que as imagens ficam fantásticas neles. Mas nunca compreendi porque as pessoas desejam ver na tela pequena essas imagens fantásticas, disponíveis em grande formato. Fico feliz que vejam, mas nunca entendi o por quê.

Cristiane Fontinha - Você acha que os fotógrafos estão mudando o jeito que capturam a imagem pensando nos tablets?

Alan Taylor - Eu não sou fotógrafo, então não posso falar por eles. Mas sei que, em geral, enquanto eles estão fotografando, fazem uma série de coisas. Os profissionais estão tendo que pensar e fazer várias coisas ao mesmo tempo. Pensando na apresentação, no formato mais horizontal, além do vertical, para dar opção ao cliente que está comprando a fotografia. Algumas, por exemplo, se apresentam melhor com thumbnails, miniaturas que representam a fotografia do site. Não sei se o fotógrafo está sempre buscando uma imagem icônica, mas como editor algumas vezes procuro por uma fotografia representativa, que se destaque. Talvez não seja a melhor fotografia, talvez não seja a mais forte, mas o ícone da história que você está tentando contar.

Cristiane Fontinha - Você frequentemente escolhe fotografias horizontais, certo?

Alan Taylor - Sim, a maioria das vezes.

Cristiane Fontinha - Isso tem uma razão?

Alan Taylor-Gosto que o observador possa ver o máximo possível da imagem. Se escolher uma imagem vertical, parte dela ficará fora da tela enquanto você a vê. Você não consegue colocar a imagem inteira na tela.

Cristiane Fontinha - Então, ao que tudo indica, os fotógrafos terão que mudar o jeito de fotografar.

Alan Taylor - Sim, se você pensar na forma como observamos as coisas, na horizontal. Tudo é horizontal. É o melhor jeito que cabe na mente. Quase nada é quadrado ou vertical. Para se ver uma fotografia 
vertical de forma decente na tela você teria que encolhê-la e colocar tarjas pretas laterais para caberem na tela ou dar um zoom in. Eu as uso, mas definitivamente não são as minhas preferidas.

Cristiane Fontinha - Você tem publicado algumas fotografias panorâmicas. Você acha ser viável no jornalismo a utilização de fotografias em 360 graus ou 3D?

Alan Taylor - Eu penso que são recursos fantásicos, mas algumas vezes pode ser apenas uma bossa, uma novidade. A técnica pode ser interessante, mas pode não acrescentar muito. Você pode fazer girar e ver tudo, mas você não necessariamente vê mais, você só vê muito.

Cristiane Fontinha -O que você busca em uma fotografia quando está editando uma história?

Alan Taylor - Grandes fotografias para mim são as que têm conteúdo editorial, notícia e um pouco de arte ao mesmo tempo. Eu tenho um imenso respeito pelos fotógrafos. Não consigo compreender como, algumas vezes, conseguem, mantendo o foco e a atenção, enquadrar corretamente tudo na cena, maravilhosamente, e com uma boa luz. É extraordinário conseguir fazer isso dia após dia. Eu penso nos fotógrafos que estão em áreas de conflito. Quando se tem balas voando e foguetes aterrisando não muito longe dali, você tem que ser institivo para não simplesmente tomar qualquer imagem, mas sim uma fotografia realmente boa.

Cristiane Fontinha - Você edita uma nova história todos os dias? Esse é seu objetivo?

Alan Taylor - Não. Tenho publicado algumas vezes na semana. Algumas semanas eu publico quatro vezes, outras cinco, outras três, depende do que esteja acontecendo. Temos tido histórias maravilhosas estes últimos tempos, então tenho editado com mais frequência. 